\title{
Response of lymphatic tissues to dietary supplementation of Nigella sativa and Curcuma longa in broilers challenged with Pasteurella multocida.
}

Muhammad Akmal Raheem ${ }^{1}$, Hu Jiangang1, Dongdong Yin'1, Mei Xue', Kashif ur Rehman², Muhammad Ajwad Rahim ${ }^{3}$, Yi Gu' ${ }^{1}$, Dandan Fu1 ${ }^{1}$, Xiangjun Song1, Jian Tu${ }^{1}$, Ibrar Muhammad Khan $^{4}$, M.Y. Tipu ${ }^{5}$ and Kezong Qi ${ }^{*}$

1 A Key Laboratory of Veterinary Pathobiology and Disease Control, College of Animal Science and Technology, Anhui Agricultural University, Hefei, 230036, PR China; dr.akmalraheem1362@yahoo.com (M.A.R.); vethjg@163.com (H.J.G.); yindd160@163.com (D. D.Y.); 1178064565@qq.com (M.X.); 296892447@qq.com (Y.G.); fudandan2020@126.com (D.F.); 13275769789@126.com (X.S.); tujian1980@126.com (J.T.)

2 Livestock and Dairy Development Department, Poultry Research Institute, Rawalpindi, Punjab, Pakistan; drkashif706@hotmail.com (K.R.)

3 Department of Zoology, Ghazi University D. G. Khan, 32200, Punjab, Pakistan; majwadrahim1993@outlook.com (M.A.R.)

4 Anhui Provincial Laboratory of Local Livestock and Poultry Genetical Resource Conservation and Breeding, College of Animal Science and Technology, Anhui Agricultural University, Hefei, Anhui, China, 230036

5 Faculty of Pathology, University of Veterinary and Animal Sciences, Lahore 54000, Punjab, Pakistan; yasintipu@uvas.edu.pk (M.Y.T.)

* Correspondence: qkz@ahau.edu.cn (K.Q.)

Abstract: The antibiotic residues and pathogenic resistance against the drug are very common in poultry due to usage of antibiotics in their feed. It is the need of the time to use natural feed additives as effective alternatives instead of synthetic antibiotic. The aim of this study was to investigate the immune response of Nigella sativa and Curcuma longa in broilers under biological stress against Pasteurella multocida. The total 100, one-day old chicks were divided into 5 groups. The Groups 1 and 2 were served as control negative and control positive. Both control groups were receiving simple diet without any natural feed additives but infection was given in Group 2 at day 28 with the dose of $5.14 \times 10^{7} \mathrm{CFU}$ by IV. Groups 3A \& 3B were offered $2 \%$ seed powder of Nigella sativa, Groups 4A \& 4B were offered Curcuma longa $1 \%$ in powdered form and Group 5A \& 5B were offered both Curcuma longa $1 \%$ \& Nigella sativa $2 \%$ in feed from day 1 and groups $3 \mathrm{~B}, 4 \mathrm{~B}$ and $5 \mathrm{~B}$ were challenged with Pasteurella multocida. The Haemagglutination inhibition titter against Newcastle Disease Virus (NDV), feed conversion ratio, mortality, gross and histopathology were studied. The results of this study revealed that haemagglutination inhibition titers against NDV were highly significant $(\mathrm{P}<0.05)$ in treated groups, highest titers $(3 \mathrm{~A} 6.8,3 \mathrm{~B} 6.4$ and $5 \mathrm{~A} 7.2)$ were obtained from treated Group. The feed conversion ratio (FCR) of Nigella sativa + Curcuma longa treated Groups (5A 1.57 and 3A 1.76) were higher as compared to other non-treated groups. The gross and histopathological changes were much severe in control positive, but less changes were seen in treated groups. Therefore, we recommend that natural feed additives; black cumin (Nigella sativa) and turmeric (Curcuma longa) act as immune enhancer in broilers against Pasteurella multocida.

Keywords: Nigella sativa; Curcuma longa; Pasteurella multocida; feed conversion ratio; gross pathological changes; histopathological changes 


\section{Introduction}

The Poultry industry is one of the most imperative sectors of agriculture in the world. It is growing rapidly as a dynamic industry in the South Asian countries. The wonderful role of commercial broilers and layers is to fulfill the growing demand of protein in the form of eggs and meats [1]. The Pasteurella multocida is a gram-negative bacterium that causes a variety of diseases in different animals such as fowl cholera in poultry [2]. Fowl cholera is a usually infectious avian bacterial disease causing high morbidity and mortality, thus resulting in huge financial losses in poultry industry $[3,4]$.

Since the ancient times to improve animal health, productivity and profitability different strategies have been applied [5]. Antibiotics used as an antibiotic growth promoter (AGP) in feed of livestock and also used as sub-therapeutic [6]. However, the use of antibiotics as feed additives is dangerous due to cross-resistance and also deposits into the tissues which affect the meat quality [7]. From 2006, the European Union (EU) has banned the use of AGP in animal feed because of its potential risks [8]. Now the demand of alternative substances (antibiotic-free) is growing rapidly [9].

Phytogenic Feed Additives (PFA) are products which are obtained from plants and used in human and animal feed to improve their health status, and also increase digestive enzymes secretion [10]. PFA can be available in different forms such as herbs, spices, essential oils, or oleoresin [11]. The pure forms PAF and their different combinations have been used in many in-vitro and in-vivo experiments to reveal the immune-potential, anti-inflammatory, antioxidant, anthelmintic, coccidiostatic, antiviral, and antibacterial properties [12]. The useful effects of PFA on poultry may come from feed intake and activation of digestive secretions $[13,14]$.

The black cumin (Nigella sativa) seeds are the most valuable medicinal seeds in history and widely grown in different parts of the world especially in Middle East and South Asia countries to support the health $[15,16]$. The seeds of Nigella sativa (NS) has different types of pharmacologically active substances, such as thymol, dithymoquinone, thymoquinone, carvacrol, alpha-hedrin, nigellicine-N- oxide and nigellidine which helps in strengthening of paraimmunity $[17,18]$. The seeds of Nigella sativa have been used treat coughs, dropsy, vomiting, diarrhea, obesity, abdominal pain, stomachic, hepatic disorders, intermittent fevers, asthma, rheumatism, skin diseases, diuretic, joint pain, diaphoretic, dyspepsia, carminative, migraine and chronic headache [19-22]. NS and its various extracts have antibacterial activity and also inhibit the production of aflatoxin [23]. The importance of Nigella sativa is highly increased in the treatment of several diseases, such as anti-tumor activity [24,25], antioxidant activity [26], anti-inflammatory activity [27], antibacterial activity [28] and stimulating the effects on the immune system [29]. Most of the researches shows that NS seeds have antiparasitic, anthelmintic, antidiabetic, analgesic, bronchodilator, renal protective spasmolytic and antihypertensive properties [16,30]. The grinded seeds of NS have beneficial effects on metabolism, growth and meat quality in broilers and also improve the performance layers and its egg quality [3134]. Nigella sativa and its ingredients enhanced cell mediated immunity but suppressed humoral immunity. Therefore, scientists all over the world have great interest in this seed, and NS has been extensively studied [35,36].

Curcuma longa (CL) generally known as turmeric. It is mainly used in powdered form. It has also therapeutic properties $[37,38]$. The volatile oils and curcuminoid pigments, oleoresins and extracts which are the main secondary metabolites of turmeric that are responsible for the pharmacological actions of turmeric powder $[39,40]$. Turmeric is used as a blood purifier and as well as used in the prevention and treatment of skin diseases [41]. It was found that the main functions of curcuma rhizome were hepatoprptective [42,43], anti-inflammatory [44,45], antimicrobial [46,47], antiviral [48], antifungal [49], wound healing [44], anti-tumor [50], anti-venom [51] and immunomodulator [52]. The results revealed the therapeutic potential of CL crude extracts, including polysaccharides and curcuminoids as a supportive supplement for cancer patients whose immune systems were crushed during chemotherapy. The effect of CL was investigated by the performance of broilers. The CL increases the total number of leukocytes and erythrocytes count. Turmeric has no adverse effects on health and food so it has been concluded that turmeric can be used as a feed additive to improve the overall performance of broiler [53]. 
Therefore, this study was conducted to evaluate the effects of perennial herbs Nigella sativa and Curcuma longa on immune system and growth performance broiler chickens against Pasteurella munltocida infection. The hemagglutination inhibition, feed conversion ratio, mortality, gross and histopathology was performed for the objectives of this study.

\section{Materials and Methods}

\subsection{Animals \& Ethics statement.}

We used the one-day old Arbor Acre (AA) broiler as experimental birds that were purchased from Big Bird Group of Companies Ltd (Punjab, Pakistan). The one-day old AA broiler were kept under healthy and controlled environment, temperature were also maintained according to the age and behavior of birds $\left(28-33^{\circ} \mathrm{C}\right)$. We tried our best to provide them a clean and comfortable environment. The care of all birds were taken according to the Institutional Animal Care and Use Committee (IACUS) guidelines by the department of pathology, Faculty of Veterinary Sciences, University of Veterinary and Animal Sciences, Lahore Pakistan (UVAS 2019-010). We are very sorry to do the experiments at the cost of their lives but these chicks made a great contribution in scientific research to save more chickens in future and improve the health of human being.

\subsection{Bacterial strain and media}

In this study, we used the clinical strain of Pasteurella multocida that was obtained from Quality Control Laboratory of Ottoman Pharma, Raiwind Road Lahore. The bacteria were grown in lysogeny broth (LB) medium at $37^{\circ} \mathrm{C}$ and with shaking of $150 \mathrm{RPM}$. This study was conducted at experimental shed of Pathology Department, University of Veterinary and Animal Sciences, Lahore.

\subsection{Experimental Design}

A 100 day-old chicks were purchased from the local market and were being divided into 5 groups of 20 viz. 1, 2, 3, 4 and 5. The feed and water were given adlibtum. Group-1: was serving as non-infected non-treated control group in which no infection with bacteria and no treatment with Nigella sativa and Curcuma longa was given. Group-2: was challenged with Pasteurella multocida with dose rate of $5.14 \times 107$ CFU by IV at day 28 [54]. Group-3: was divided in to two sub groups 3A and 3B of 10 birds each. Group $3 \mathrm{~A}$ was offered Nigella sativa $2 \%$ as powder form in feed from day 1 and not challenged while group 3B was offered Nigella sativa $2 \%$ as powder form in feed from day 1 and was challenged with Pasteurella multocida at day 28. Group-4: was be divided in to two sub groups $4 \mathrm{~A}$ and $4 \mathrm{~B}$ of 10 birds each. Group $4 \mathrm{~A}$ was be offered Curcuma longa $1 \%$ as powder form in feed from day 1 and not challenged while group $4 \mathrm{~B}$ was offered Curcuma longa $1 \%$ as powder form in feed from day 1 and was challenged with Pasteurella multocida at day 28. Group-5: was divided in to two sub groups 5A and 5B of 10 birds each. Group 5A was offered both Nigella sativa 2\% and Curcuma longa 1\% as powder form in feed from day 1 and group 5B was offered both Nigella sativa $2 \%$ and Curcuma longa $1 \%$ as powder form in feed from day 1 and was challenged with Pasteurella multocida at day 28.

\subsection{Vaccination}

All routine vaccines were administered to experimental birds according to standard vaccination schedule and protocol. 
The mortality and postmortem examination record of each dead bird was carried out to determine the cause of death. Weighing the dead birds to adjust in feed efficiency and weight gain.

\subsection{Feed Conversion Ratio}

The FCR was calculated on day 42 . The average weight of all day-old chicks was 45.11 grams on day first. The feed consumption and average weight gain was calculated on 28th day of experiment to evaluate the feed conversion rate (FCR) according to the following formula [55].

\subsection{Gross Pathology}

\section{FCR: Feed consumed \\ Body weight gain}

At the end of trail (after 7 weeks), all chicks were slaughtered to observe the gross pathological changes.

\subsection{Histopathology}

After postmortem examination tissue samples from spleen, liver and lungs were quickly excised and preserved in $10 \%$ buffered formalin. The preserved tissues were quickly processed for histopathological examination. All standard protocols for histopathological examination including fixation, washing, dehydration, clearing, embedding, block preparation, sectioning and Mounting were adopted [56].

\subsection{Staining}

Eosin and Haematoxylin were used for the staining of tissue sections. Then stained slides were examined under different magnification for prominent lesions [57].

\subsection{Haemagglutination Inhibition (HI)}

On the 14th, 21st and 28th days, the ordinary plain vaccutainers (red top) were used to collect the blood sample from the wing veins of five randomly selected birds in each group. Allow blood samples to coagulate to separate the serum and for H.I test [58]. HI tests was performed to determine the antibody titer against NDV [3,59]. Reference NDV (Velogenic) antigen was obtained from University Diagnostic Lab, University of Veterinary and Animal Sciences, Lahore.

HI Positive: The prominent button formation in the bottom of micro- titration plate wells.

HI Negative: Finely clump RBCs form a uniform thin layer in the wells of micro- titration plate. HI titer was equal to the highest serum dilution level that inhibits haemagglutination activity. The geometric mean titers (GMT) of different groups was calculated.

\subsection{Statistical Analysis}

The statistical analysis was performed by SPSS 16.0 (SPSS Inc., Chicago, IL, USA). The results of all experiments were analyzed by one-way analysis of variance (ANOVA), followed by Tukey's HSD (honestly significant differences) for post-hoc testing to compare the significance $(\mathrm{P})$ between the means of different groups. $\mathrm{P}<0.05$ was considered to indicate a significant difference between the values compared.

\section{Results}




\subsection{Antibody titer against NDV in different bird's groups}

Hemagglutination Inhibition (HI) test was performed against NDV at day 14, 21, and 28 of age of flock to evaluate the immunomodulatory effects of N. sativa and C. longa in trail poultry broiler birds. The geometric mesn titer (GMT) and cumulative geometric mean (CGMT) values of HI test are described below.

The chicks which were reared on simple feed without any infection (Group 1) have low immunity as compared to the birds which were fed on natural feed additives; NS, CL and a mix of these two. The GMT values of the HI test of simple feed taking birds against NDV on day 14, 21, and 28 were $\log _{2^{4.4}}, \log _{2^{5}}$, and $\log _{2^{5.2}}$ calculated respectively, and the CGMT value was $4.86 \pm 0.41$ (Table 1). The chicks were taking simple feed without any natural feed additives but challenged with Pasteurella multocida at day 28 (Group 2) has the lowest immunity as compared to all other birds. The GMT values of the HI test against NDV on day 14,21 , and 28 were $\log _{2} 4.4, \log _{2} 4.8$, and $\log _{2} 4$ calculated respectively, and the CGMT value of these chickens was $4.40 \pm 0.40$ (Table 1). The chicks offered $2 \%$ NS powder in the feed from day 1st to the end of the trail and no challenge was given has greater immune response as compared to simple feed taking birds. The GMT values of the HI test against NDV on day 14,21 , and 28 were $\log _{2^{5.8}}, \log _{2^{6}}$, and $\log _{2} 2^{6.8}$ calculated respectively, and the CGMT value of these chicks was $6.20 \pm \mathbf{0 . 5 2}$ (Table 1 ). The chicks which are eating $2 \%$ NS powder as a feed additives but challenged with Pasteurella multocida on day 28 also has high immune response. The GMT values of the HI test against NDV on day 14,21 , and 28 were $\log _{2}{ }^{6}, \log _{2}{ }^{6.2}$, and $\log _{2}{ }^{6.4}$ calculated respectively, and the CGMT value was $\mathbf{6 . 2 0} \pm \mathbf{0 . 2 0}$ (Table 1) which was high immunity. The chicks which were receiving 1\% CL powder in the feed from day 1st to end of the trail and no challenge was given, have greater immune as response as compared to the simple meal taking chicks. The GMT values of the HI test of CL taking birds against NDV on day 14,21 , and 28 were $\log _{2}{ }^{5}, \log _{2}{ }^{5.4}$, and $\log _{2^{6}} \operatorname{calculated}$ respectively, and the CGMT value of these CL taking birds was $\mathbf{5 . 4 6} \pm \mathbf{0 . 5 0}$ (Table 1). The chicks receiving $1 \% \mathrm{CL}$ powder in feed from day 1st to the end of the trail but challenge with Pasteurella multocida on day 28 , have high immunity. The GMT values of the HI test of CL chicks against NDV on day 14,21 , and 28 were $\log _{2}{ }^{5}, \log _{2} 6$, and $\log _{2}{ }^{5}$ respectively calculated and the CGMT was $5.13 \pm 0.1$ (Table 1). The birds were fed on mix feed ( $2 \% \mathrm{NS}+1 \% \mathrm{CL})$ as a feed additives in their feed from day 1st to end of trail and no challenged was given. The GMT values of HI test of mix feed taking birds against NDV at day 14,21 , and 28 were $\log _{2} 6.4, \log _{2} 6.8$, and $\log _{2} 2^{7.2}$ calculated respectively, and the CGMT value was $6.80 \pm 0.40$ (Table 1). The birds were was $2 \%$ NS $+1 \%$ CL as a powder form in their feed from day 1st to the end of the trail but challenged with Pasteurella multocida on day 28 have greatest immune response against the infection. The GMT values of HI test of $2 \% \mathrm{NS}+1 \% \mathrm{CL}$ taking birds against NDV at day 14,21 , and 28 were $\log _{2}{ }^{6.6}, \log _{2} 6.8$, and $\log _{2} 7$ calculated respectively, and CGMT value was $6.80 \pm 0.20$ (Table 1 ).

Table 1. Antibody titer against NDV in different bird groups (mean \pm standard error; $n=3$ ).

\begin{tabular}{ccccc}
\hline \multirow{2}{*}{ Groups } & \multicolumn{3}{c}{ Days (HI titer) GMT } & CGMT \pm S.D \\
\cline { 2 - 4 } & 14 Days & 21 Days & 28 Days & \\
\hline Groups 1 & 4.4 & 5 & 5.2 & $4.86 \pm 0.41$ \\
Groups 2 & 4.4 & 4.8 & 4 & $4.40 \pm 0.40$ \\
Groups 3A & 5.8 & 6 & 6.8 & $6.20 \pm 0.52$ \\
Groups 3B & 6 & 6.2 & 6.4 & $6.20 \pm 0.20$ \\
Groups 4A & 5 & 5.4 & 6 & $5.46 \pm 0.50$ \\
Groups 4B & 5 & 6 & 5 & $5.13 \pm 0.11$ \\
Groups 5A & 6.4 & 6.8 & 7.2 & $6.80 \pm 0.40$
\end{tabular}



Groups 5B
6.6
6.8
7
$6.80 \pm 0.20$

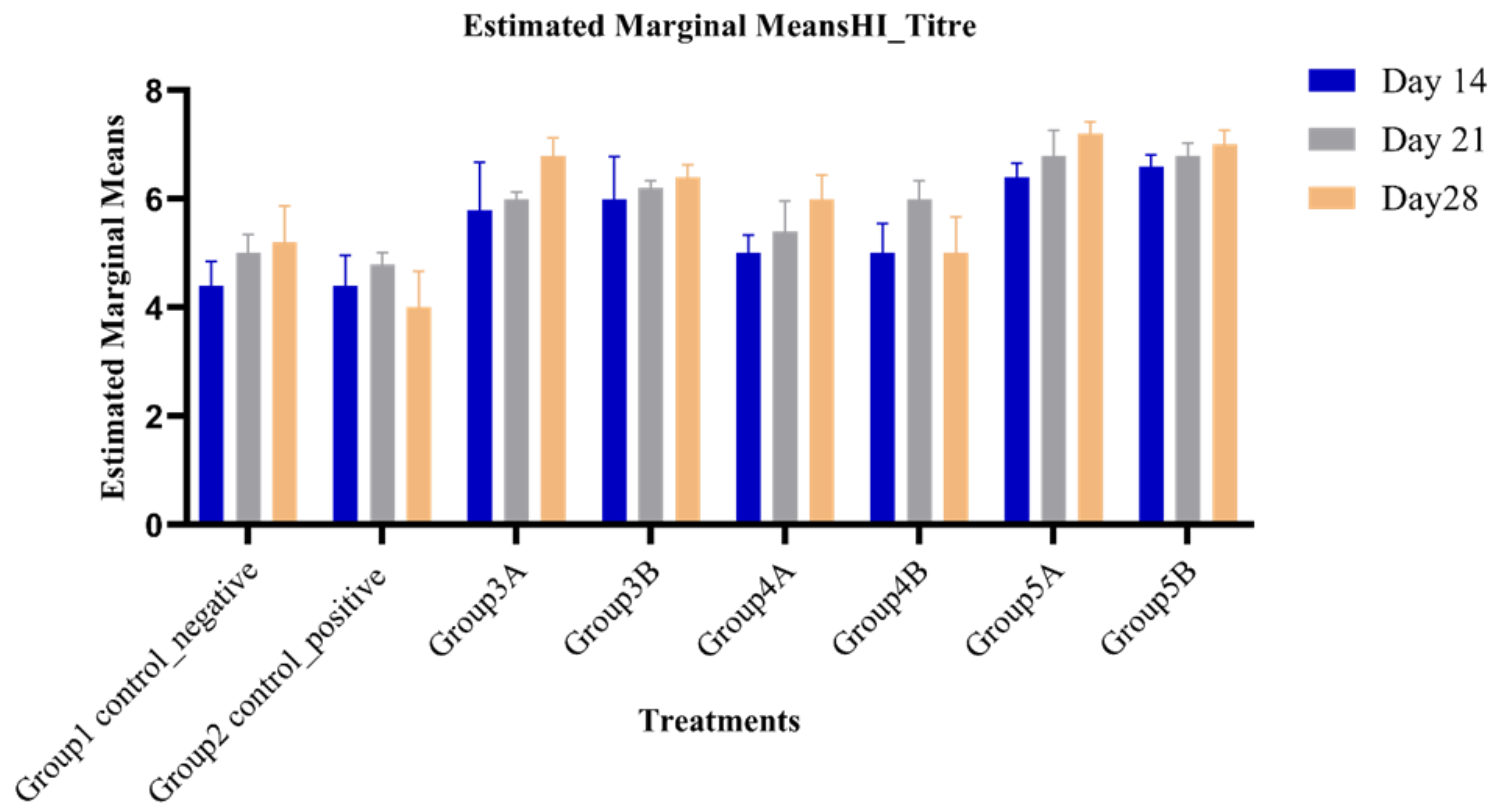

Figure 1. HI titer estimated marginal mean titer of each group, which are highly significant $(\mathrm{P}<0.05)$ from each other

\subsection{Feed Conversion Ratio of each group}

The Group 1; was serving as non-infected, non-treated control group. The average feed intake and average body weight gain was $1140 \pm 460.88 \mathrm{~g}$, and $523 \pm 189.14$ respectively calculated. The average feed conversion ratio was $2.17 \pm 0.49$ (Table 2). The Group 2; was challenged with Pasteurella multocida by IV at day 28 and that was serving as positive control in which no treatment was given. The average feed intake and average body weight gain was $518 \pm 285.28$, and $205 \pm 146.79$ respectively calculated. The average feed conversion ratio was $2.52 \pm 0.62$ (Table 2). The Group 3A; was offered $2 \%$ Nigella sativa powder in feed from day 1st to end of trail and no challenged with Pasteurella multocida. The average feed intake and average body weight gain was $1100 \pm 435.56$ and $624 \pm 241.20$ respectively calculated. The average feed conversion ratio was $1.76 \pm 0.32$ (Table 2). The Group 3B was also offered $2 \%$ Nigella sativa powder in feed from day 1 st to end of trail and challenged with Pasteurella multocida at day 28. The average feed intake and average body weight gain was $1210 \pm$ 429.46 and $586 \pm 219.96$ respectively calculated. The average feed conversion ratio was $2.06 \pm 0.39$ (Table 2). The Group 4A was offered 1\% C. longa powder in feed from day 1st to end of trail and no challenged with Pasteurella multocida. The average feed intake and average body weight gain was $1134 \pm 414.57$ and $584 \pm 222.82$ respectively calculated. The average feed conversion ratio was $1.94 \pm$ 0.32 (Table 2). The Group 4B was offered 1\% C. longa powder in feed from day 1 st to end of trail and challenged with Pasteurella multocida at day 28. The average feed intake and average body weight gain was $923 \pm 343.93$ and $415 \pm 174.94$ respectively calculated. The average feed conversion ratio was $2.22 \pm 0.44$ (Table 2). The Group 5A was offered $2 \%$ Nigella sativa and $1 \%$ C. longa as powder form in the feed from day 1st to end of trail and no challenged with Pasteurella multocida. The average feed intake and average body weight gain was $1134 \pm 418.99$ and $720 \pm 232.04$ respectively calculated. The average feed conversion ratio was $1.57 \pm 0.31$ (Table 2). The Group 5B was offered $2 \%$ Nigella sativa and $1 \%$ C. longa as powder form in the feed from day 1st to end of trail and challenged with Pasteurella multocida at day 28. The average feed intake and average body weight gain was $1110 \pm$ 404.14 and $590 \pm 207.10$ respectively calculated. The average feed conversion ratio was $1.88 \pm 0.38$ (Table 2). 
Table 2. The Feed conversion ratio of each group (mean \pm standard error; $n=3$ ).

\begin{tabular}{cccc}
\hline Groups & $\begin{array}{c}\text { Feed Consumption } \\
(\mathbf{g})\end{array}$ & Average Weight Gain (g) & Feed Conversion Ratio \\
\hline Groups 1 & $1140 \pm 460.88$ & $523 \pm 189.14$ & $2.17 \pm 0.49$ \\
Groups 2 & $518 \pm 285.28$ & $205 \pm 146.79$ & $2.52 \pm 0.62$ \\
Groups 3A & $1100 \pm 435.56$ & $624 \pm 241.20$ & $1.76 \pm 0.32$ \\
Groups 3B & $1210 \pm 429.46$ & $586 \pm 219.96$ & $2.06 \pm 0.39$ \\
Groups 4A & $1134 \pm 414.57$ & $584 \pm 222.82$ & $1.94 \pm 0.32$ \\
Groups 4B & $923 \pm 343.93$ & $415 \pm 174.94$ & $2.22 \pm 0.44$ \\
Groups 5A & $1134 \pm 418.99$ & $720 \pm 232.04$ & $1.57 \pm 0.31$ \\
Groups 5B & $1110 \pm 404.14$ & $590 \pm 207.10$ & $1.88 \pm 0.38$ \\
\hline
\end{tabular}
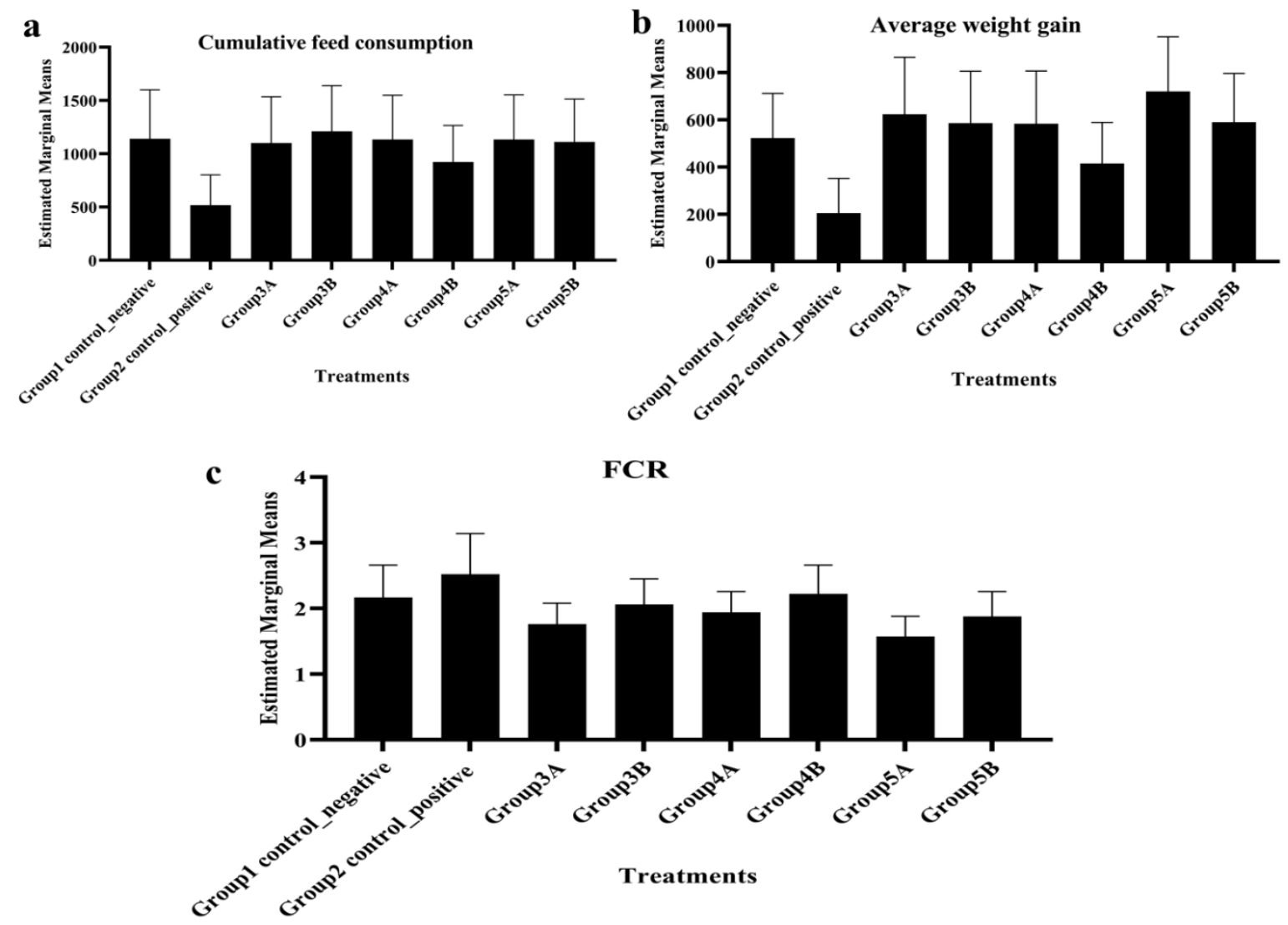

Figure 2. Cumulative feed consumption, average weight gain and FCR each group were highly significant $(\mathrm{P}<$ 0.05) from each other.

\subsection{Mortality of Birds before Challenged}

A complete record of mortality was noted on daily basis from each group of experimental birds. Before challenging Pasteurella multocida some mortality occurs in the following experimental groups. One bird out of twenty was found to be died in Group 2 (Table 3).

Table 3. Before and after infection mortality during the experiment (mean \pm standard error; $n=3$ ). Mean values followed by the same letter in the same column do not vary significantly $(\mathrm{P}<0.05)$. 


\begin{tabular}{cccccccc}
\hline & \multicolumn{9}{c}{ Days } & \multirow{2}{*}{$\begin{array}{c}\text { Total Mortality } \\
\text { Proups }\end{array}$} & $\begin{array}{c}\text { Mortality before } \\
\text { challenged }\end{array}$ & \multicolumn{4}{c}{ Mortality After Challenged } \\
\cline { 2 - 6 } & $\mathbf{2}$ & $\mathbf{3 1}$ & $\mathbf{3 4}$ & $\mathbf{3 7}$ & $\mathbf{3 9}$ & $\mathbf{4 0}$ & \\
\hline Groups 1 & 1 & 0 & 0 & 0 & 0 & 0 & $5^{\mathrm{a}}$ \\
Groups 2 & 0 & 2 & 3 & 3 & 2 & 3 & $65^{\mathrm{b}}$ \\
Groups 3A & 0 & 0 & 0 & 0 & 0 & 0 & $0^{\mathrm{a}}$ \\
Groups 3B & 0 & 0 & 1 & 0 & 0 & 0 & $10^{\mathrm{a}}$ \\
Groups 4A & 0 & 0 & 0 & 0 & 0 & 0 & $0^{\mathrm{a}}$ \\
Groups 4B & 0 & 1 & 1 & 0 & 0 & 0 & $20^{\mathrm{a}}$ \\
Groups 5A & 0 & 0 & 0 & 0 & 0 & 0 & $0^{\mathrm{a}}$ \\
Groups 5B & 0 & 0 & 0 & 0 & 0 & 0 & $0^{\mathrm{a}}$ \\
\hline
\end{tabular}

\subsection{Clinical signs and necropsy findings after challenged}

The N. sativa, C. longa and combination of both N. sativa and C. longa in powder form was given in the feed from day 1st to all groups. After challenging Pasteurella multocida at day 28 in Group $2,3 \mathrm{~B}, 4 \mathrm{~B}$ and $5 \mathrm{~B}$. All groups were closely watched for any clinical sign of disease. All experimental birds were taking their feed and water properly till 48 hours but after that time most of the birds from Group-2 (positive control) show depression and poor feed consumption, within a 1st week after infection the birds of Group-2 showed sever type of clinical signs such as fever, anorexia, ruffled feathers, mucous discharge from mouth and white diarrhea arthritis, and reduce feed consumption. Other groups were also showed clinical signs and symptoms such as reduced feed and low weight gain. At day 31 two birds from Group-2, one bird from Group-4B, but at day 34 three birds from group Group-2, one from Group-3B and one from Group-4B. The number of birds died from Group 2 were 3,2 and 3 at day 37, 39 and 40 respectively but the most birds of Groups 3B, 4B, and 5B were showing activeness, started feeding and getting towards recovery.

\subsection{Necropsy Findings}

The Group 2 necropsy findings were; hemorrhagic carcass, fibrino necrotic dermatitis on abdomen and breast muscle. Petechial hemorrhages on heart and liver, liver was enlarged, swollen, and cooked appearance. Numerous small, irregular shaped yellow necrotic foci were present on liver. Large size spleen in some birds, hemorrhagic and odematic lungs were also found. Dark friable lungs in some birds were also obvious. Petechial hemorrhages on intestine, duodenal enteritis and caseous material in hock joint.

\subsection{Gross Pathological Changes}



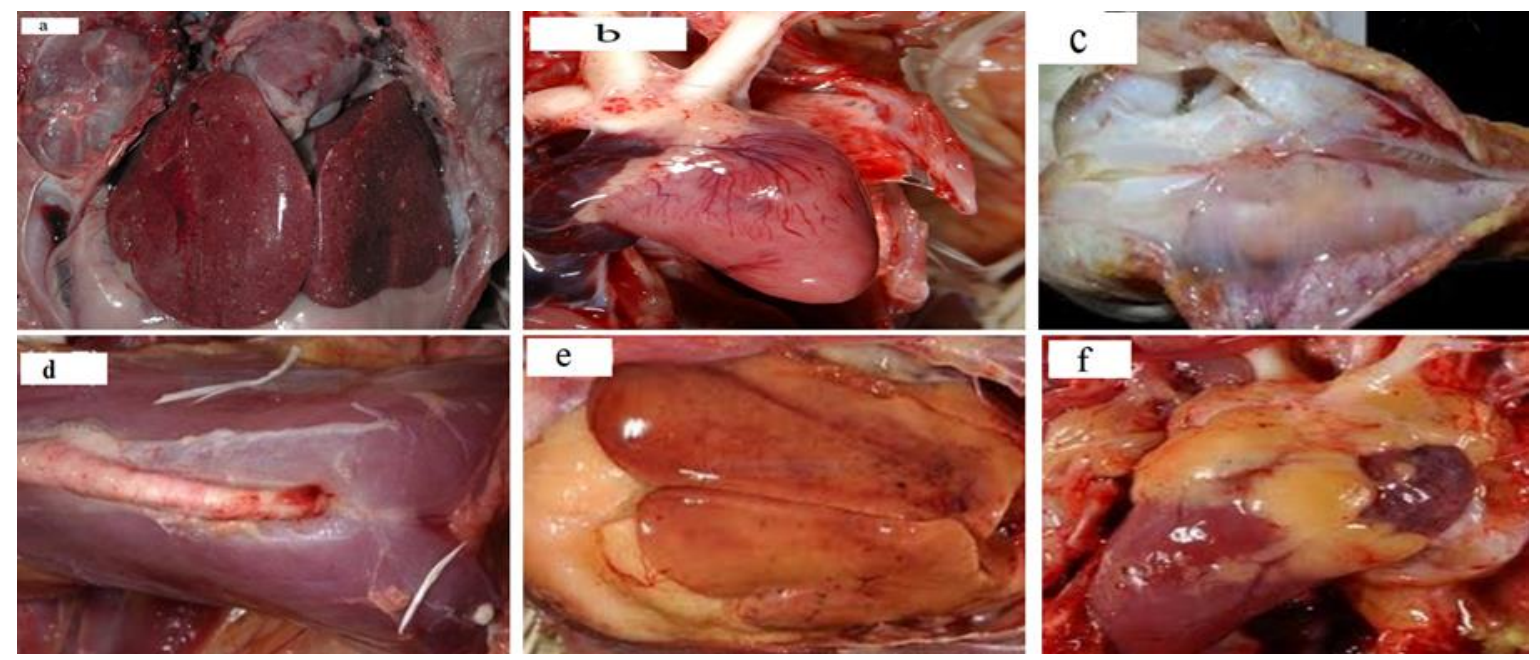

Fig 3. (a) Group -2 showing numerous, small, irregular shaped yellow necrotic foci on liver; (b) Group -2 showing hemorrhages on heart; (c) Group-2 representing caseous material in joints; (d) Group-2 representing the swelling of sternal bursa; (e) Group-4B representing enlarged, swollen, cooked appearance of liver and petechial hemorrhages; (f) Group-4B showing hemorrhages on heart.

\subsection{Histopathology}

\subsubsection{Group-1 (Control Negative)}

Served as control negative group, in which no natural feed additives and no challenged were given. The Figure-4a showing normal liver section; histologically it is divided into two lobules. The central and peripheral lobule, central lobule is the central vein and periphery lobule is portal triads. Under 40X magnification, the liver cells looks polygonal or cuboidal in shape that have large, single and spherical shaped nuclei in the center. Sinusoids are capillaries which have wide sinusoidal lumens and they are lined by a discontinuous endothelium and large intercellular gaps. These sinusoids provides maximum exchange of materials between blood and hepatocytes. Figure $4 \mathrm{~b}$ showing normal histologic appearance of the spleen. The lymphocytes gathered around the splenic arteriole and form white pulp. Red pulp comprises of many splenic sinusoids. $75 \%$ of splenic volume is red pulp while white pulp is separated by marginal zone. Figure $4 \mathrm{c}$ representing normal histologic appearance of lungs tissue sections. The tissues of the lungs are composed of thin-walled alveoli and alveoli are composed of single layer of squamous epithelium. This slide contains sections of many bronchioles of various sized. Bronchioles can be recognized by the fact that they are lined by cuboidal epithelium (smaller bronchioles leading to alveoli) or ciliated columnar epithelium (larger bronchioles)
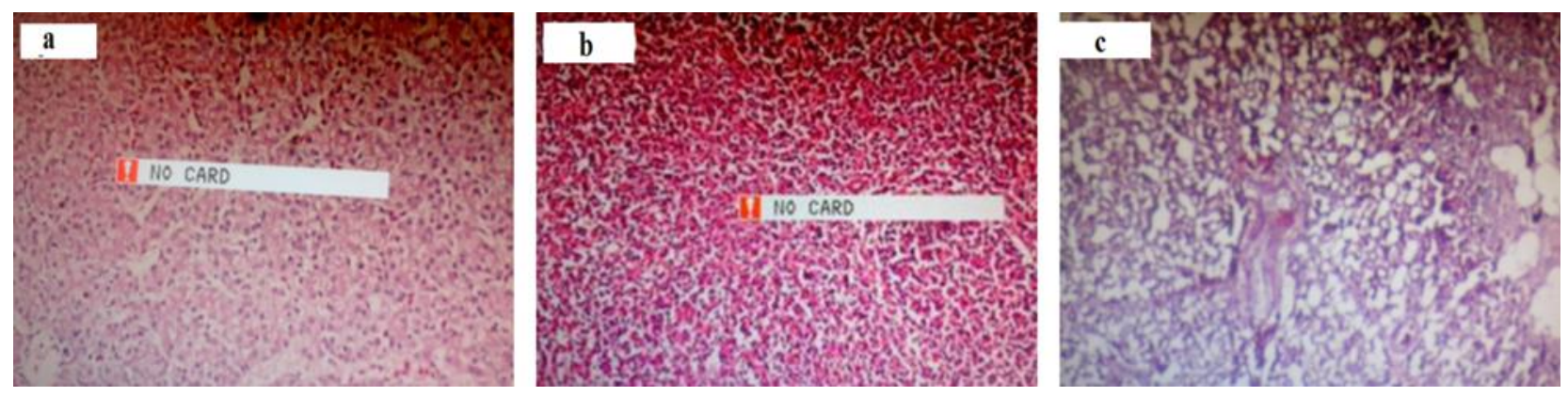

Figure 4. (a) Control negative group showing liver section normal; (b) Control negative group showing spleen section normal; (c) Control negative group showing Lungs Section Normal. 


\subsubsection{Group-2 (Control Positive)}

This group served as a positive control. After giving infection at day 28, total 13 birds were died out of 20 till the end of experiments. On histopathology liver, spleen and lungs showed specific microscopic lesions associated with Pasteurella multocida infection.
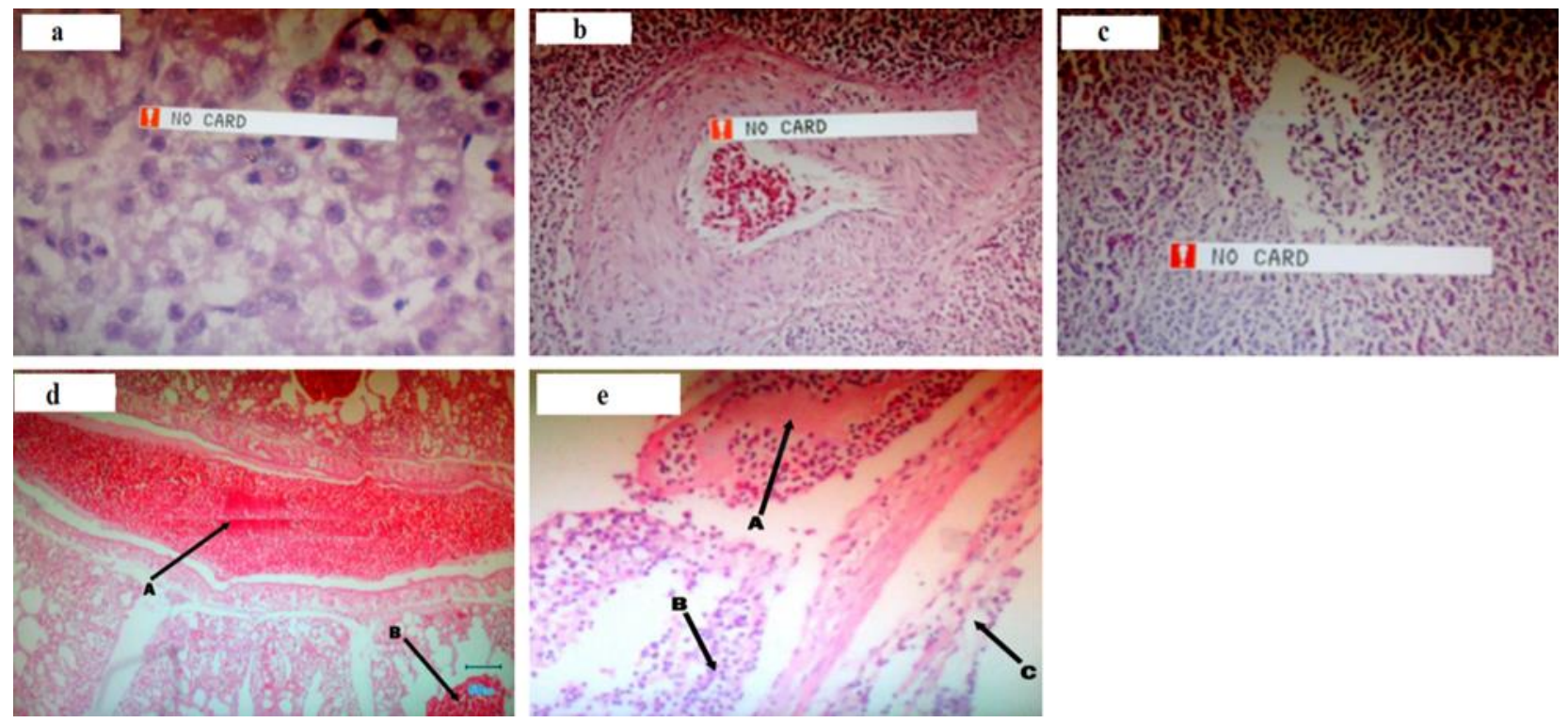

Figure 5. (a) Liver section showing congestion, infiltration of inflammatory cell, fatty changes and coagulative necrosis of hepatocyte can also be seen; (b) Spleen section showing hyperemia and congestion; (c) Spleen section showing congestion, hyperemia, atrophy of cell, dead tissue accumulation, blast cell accumulation, degeneration and necrosis of parenchyma; (d) Lungs section showing (A) Engorgement of the Blood vessel with RBCs, (B) Congestion of RBCs in mesobronchus; (e) Lungs section showing (A) Pulmonary odema, (B) Infiltration of heterophils, (C) Sloughing of the epithelium

\subsubsection{Group-3B (Infection + Nigella sativa)}
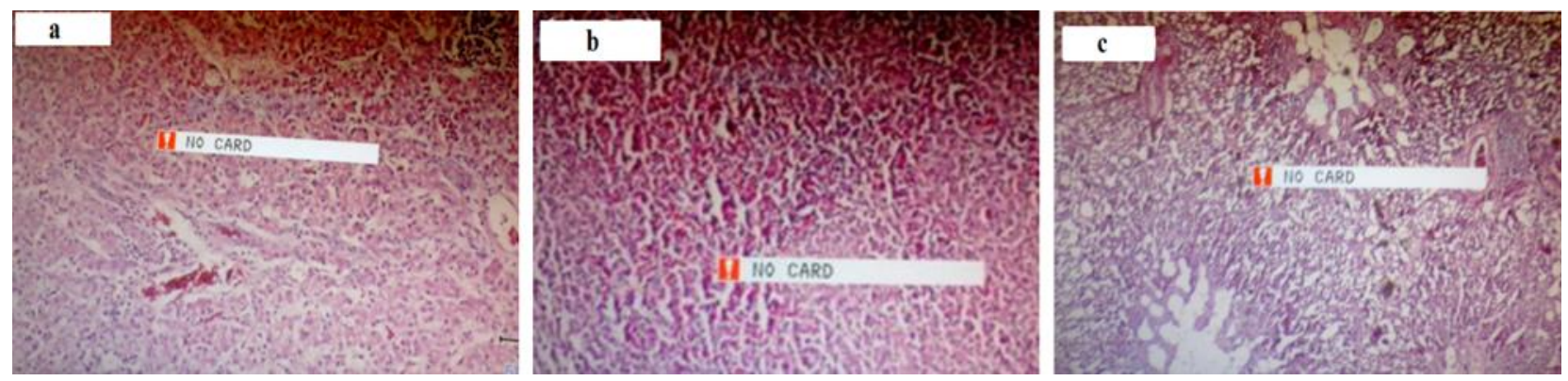

Fig 6. (a) Liver section of the morphology of all hepatocytes is normal; (b) Spleen section of the morphology of all cells is normal; (c) Lungs section morphology of all cells is normal. 


\subsubsection{Group-4B (Infection + Curcuma longa)}
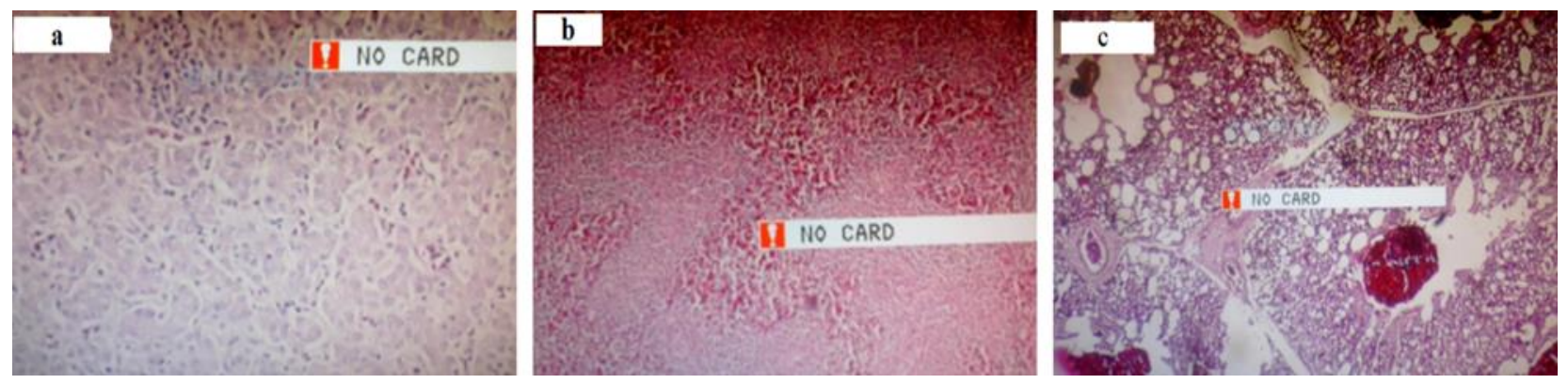

Fig 7. (a) Liver section representing a mild congestion and mild fatty change; (b) Spleen section representing a mild congestion; (c) Lungs section representing a mild congestion

\subsubsection{Group-5B (Infection + Curcuma longa + Nigella sativa)}
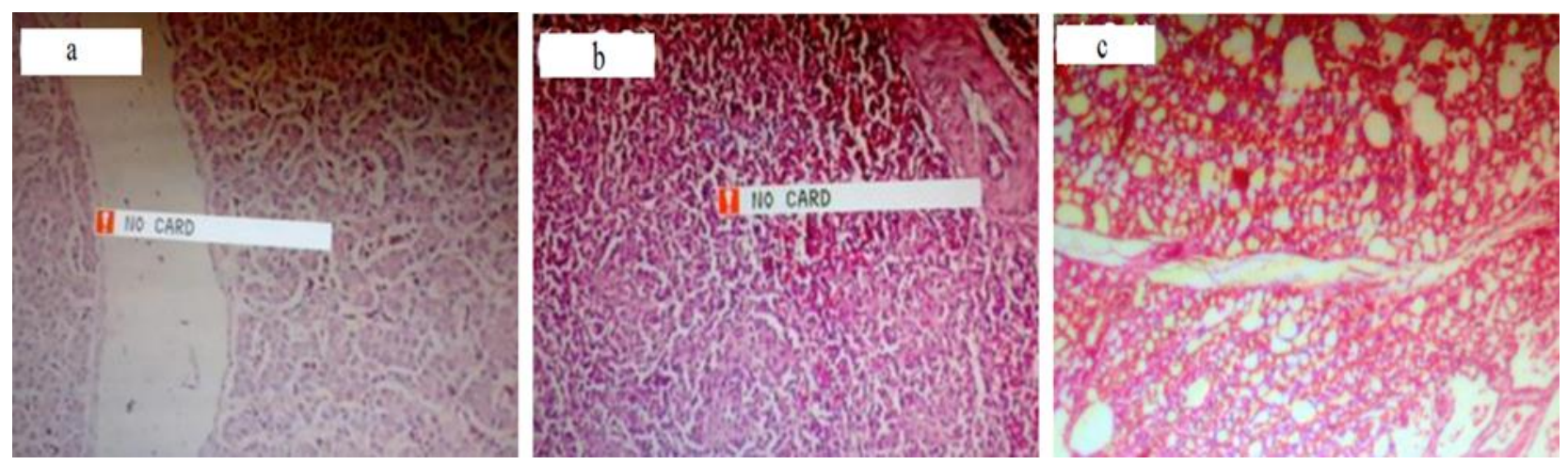

Fig 8. (a) Normal liver section; (b) Spleen section representing a normal section; (c) Lungs section representing a normal section

\section{Discussion}

This study was carried out to check the response of lymphatic tissue of broilers chicken that have been experimentally challenged with Pasteurella multocida and supplemented with Nigella sativa and Curcuma longa. The experiment was conducted to evaluate the protective and as well as immunomodulatory properties of Nigella sativa and Curcuma longa in broilers birds. The number of dead bird in group- 1 was one, where as in group 2, 3A, 3B, 4A, 4B, $5 \mathrm{~A}$ and $5 \mathrm{~B}$ were 13, 0, 1, 0, 2, 0, and 0 . All these groups were highly significant $(\mathrm{P}<0.05)$ from each other. But in the study of $[60]$ the results was that the average percentage of mortality rate (MR) was relatively high (23.6\%) in positive control group.

The most typical symptom in acute case was a green diarrhea but in chronic case inflammation of hemorrhagic carcass, hock joints, sternal bursa and foot pads. Petechial hemorrhages on heart and liver. Liver was enlarged, swollen, and cooked appearance. Numerous small, irregular shaped yellow necrotic foci were present on liver. Large size spleen in some birds, hemorrhagic and odematic lungs were also found. Dark friable lungs in some birds were also obvious. Petechial hemorrhages on intestine, duodenal enteritis and caseous material in hock joint [61,62]. Mostly all other birds were remain save due to immunomodulatory and antibacterial effect of Nigella sativa and Curcuma longa, our results are lined with [63], according to his study black seed (Nigella sative ) increased the total WBCs and the difference was significant for the white hens $(\mathrm{p}<0.02)$.

Black seed generally enhanced cell-mediated immune response and antibody titer. In addition to its anti-viral and anti-helminthic effects, N. sativa showed also anti-bacterial activity such as Grampositive and Gram negative bacterial strains [64]. The birds of receiving CL (Group 4A and 4B) in their feed were also immune against Pasteurella multocida that's why they remain normal after infection and our results are lined with [65]. 
In our study the $\mathrm{HI}$ titer of all experimental groups was measured at day 14, 21 and 28. The CGMT of group 1, 2, 3A, 3B, 4A, 4B, 5A and 5B was $4.86 \pm 0.41,4.40 \pm 0.40,6.20 \pm 0.52,6.20 \pm 0.20,5.46$ $\pm 0.50,5.13 \pm 0.11,6.80 \pm 0.40$ and $6.80 \pm 0.20$ respectively. These CGMT titers were significantly different from each other but according to the study of [66] revealed that the inclusion of Curcuma longa (CL) in poultry diets improved antibody titer and there were a significant difference in feed consumption. At the same time there was no significant difference in PCV, RBC and $\mathrm{Hb}$. WBC while there was significant difference in $\mathrm{H} / \mathrm{L}$ ratio, albumin and globulin. Significantly $(\mathrm{P}<0.05)$ higher level of globulin, suggested that birds of treated group had better humeral immune status, as compare to control group. Results indicate that powder of Nigella sativa seed increase antibody titer in broiler birds [67]. But the birds supplemented with both Nigella sativa and Curcuma longa have greater effect on blood serum and increase antibody titer.

The FCR of all experimental groups was measured at day 1, 7, 14, 21, 28, 35 and 42 . The FCR of group $1,2,3 \mathrm{~A}, 3 \mathrm{~B}, 4 \mathrm{~A}, 4 \mathrm{~B}, 5 \mathrm{~A}$ and $5 \mathrm{~B}$ was $2.17 \pm 0.49,2.52 \pm 0.62,1.76 \pm 0.32,2.06 \pm 0.39,1.94 \pm 0.32$, $2.22 \pm 0.44,1.57 \pm 0.31$ and $1.88 \pm 0.38$ respectively. Curcuma longa effect on the FCR of birds so that these finding are in line with [68]. These results are also revealed by [69]. Supplementation of $N$. sativa in the broiler ration significantly $(\mathrm{P}<0.05)$ improved the weight of the birds of various groups as compared to those of control group [70] and supported by [71]. The cumulative effect of NS and CL has greater effect on FCR of broiler than individually used these products.

Histopathology of NS taking birds was normal because NS have different types of pharmacologically active substances like thymol, dithymoquinone, thymoquinone, carvacrol, alphahedrin, nigellicine-N- oxide and nigellidine. These substances are effective in the treatment of various ailments and proved to be beneficial in improving immunity [72]. Nigella sativa is one of the most valued medicinal seeds in the history [73]. Nigella sativa (NS) is a phytogenic immunostimulants that help in establishment and strengthening of para immunity [15]. The histology of CL supplemented birds were also normal due to curcuminoid pigments (diarylheptanoids; 30-45\%) and volatile oil (15$20 \%)$; which contains zingiberene $(25 \%)$, turmerone $(60 \%)$, and minor amounts of sesquiterpenes, phellandrene, eucalyptol, sabinene and borneol [74,75]. In current years, the assessment of antioxidant power of foods has got abundant attention. Most work has been done on the anticancer and antioxidant activities of compounds obtained from the rhizomes of CL. CL has been widely used in both dried and fresh forms as a blood purifier, tonic and stomachache relief, and externally in the treatment and prevention of skin diseases [76]. The foremost actions of curcuma rhizome have been found to be hepatoprotective, anti-inflammatory, anti-microbial, antiviral, antifungal, wound healing, antitumour, and antivenom agents [48,77]. The recent studies have also revealed the immunomodulatory properties of hot water extracts CL and were also examined using human peripheral blood mononuclear cells (PBMC). In an effort to separate the active components liable for the activities, more partition with ethanol, ethyl acetate and $\mathrm{N}$-butanol, gradually were done. The productions of cytokines (TNF, TGF, CSF, GM, IL-1, IL-5, IL-6, IL-8, IL-10, IL-13, etc.) have been moderated by a polysaccharide-enriched portion as shown in ELISA and cytokine protein array [78]. This study clearly indicates that these two herbal products Nigella sativa and Curcuma longa have high immunomodulatory and antibacterial effects. So these products are useful against Pasteurella multocida.

\section{Conclusions}

The use of natural feed additives to treat common medical diseases is a novel idea but still challenging step in medicine. These traditional medicinal plants have received much attention due to many reasons such as low adverse effect, ease of access, and low cost as compared to synthetic medicines. The inclusion of CL and NS as an alternative to synthetic antibiotics in poultry feed, have several benefits due to its antimicrobial and antioxidant properties. The results of this study indicated that the supplementation of natural feed additives CL and NS improves the immune status, FCR, digestibility, overall growth performance of broiler and also proves their effectiveness against Pasteurella multocida as compared to control group. The CL and NS decreased abdominal fat and blood cholesterol level in blood diseases, but also that they may serve as catalysts for future research 
to demonstrate the efficacy and safety of both (CL and NS) for the treatment of a many human diseases. Moreover, the dietary supplementation of CL and NS may lead to the development of low cholesterol chicken meat as demanded by health-conscious consumers. The further researches are needed to get better understanding the effect of natural feed additives in poultry production and their beneficial impact on human health.

Author Contributions: Conceptualization; Kezong Qi and M.Y. Tipu, Methodology; Muhammad Akmal Raheem, Software; Mei Xue, Dandan Fu, Validation; Hu Jiangang, Dongdong Yin and Yi Gu, Formal analysis; Muhammad Ajwad Rahim, Investigation; Kezong Qi, Jian Tu and Xiangjun Song, Resources; Muhammad Akmal Raheem, Data curation; Kashif ur Rehman and Ibrar Muhammad Khan; writing-original draft preparation; Muhammad Akmal Raheem, Writing-review and editing; Kashif ur Rehman, Visualization; Muhammad Ajwad Rahim, Supervision; Kezong Qi, Project administration; Jian Tu and Xiangjun Song, Funding acquisition; Kezong Qi.

Funding: Please add: This research was funded by National Natural Science Foundation of China: 31772707 and the University Synergy Innovation Program of Anhui Province: GXXT-2019-035.

Acknowledgments: In this section you can acknowledge any support given which is not covered by the author contribution or funding sections. This may include administrative and technical support, or donations in kind (e.g., materials used for experiments).

Conflicts of Interest: The authors declare no conflict of interest.

\section{References}

1. Raheem, M.A.; Xue, M.; Ahmad, H.I.; Ahmad, M.Z.; Tipu, M.Y.; Afzal, G.; Song, X.; Rahim, M.A.; Qi, K. Adaptation to host-specific bacterial pathogens drive rapid evolution of novel PhoP/PhoQ regulation pathway modulating the virulence. Microbial Pathogenesis 2020, 141, 103997.

2. Peng, Z.; Wang, X.; Zhou, R.; Chen, H.; Wilson, B.A.; Wu, B. Pasteurella multocida: genotypes and genomics. Microbiology and Molecular Biology Reviews 2019, 83, e00014--19.

3. Baksi, S.; Rao, N.; Khan, M.; Chauhan, P.; Chauhan, A. Efficacy of Inactivated Fowl Cholera Vaccine in Chickens. PSM Veterinary Research 2018, 3, 32-35.

4. Poolperm, P.; Apinda, N.; Kataoka, Y.; Suriyasathaporn, W.; Tragoolpua, K.; Sawada, T.; Sthitmatee, N. Protection against Pasteurella multocida conferred by an intranasal fowl cholera vaccine in Khaki Campbell ducks. Japanese Journal of Veterinary Research 2018, 66, 239-250.

5. Yadav, S.; Jha, R. Strategies to modulate the intestinal microbiota and their effects on nutrient utilization, performance, and health of poultry. Journal of animal science and biotechnology 2019, 10, 1-11.

6. Sivagami, K.; Vignesh, V.J.; Srinivasan, R.; Divyapriya, G.; Nambi, I.M. Antibiotic usage, residues and resistance genes from food animals to human and environment: An Indian scenario. Journal of Environmental Chemical Engineering 2020, 8, 102221.

7. DUTTA, T.K.; YADAV, S.K.; CHATTERJEE, A. ANTIBIOTICS AS FEED ADDITIVES FOR LIVESTOCK: HUMAN HEALTH CONCERNS. Indian J. Anim. Hlth 2019, 58, 121-136.

8. Bennani, H.; Mateus, A.; Mays, N.; Eastmure, E.; Stärk, K.D.C.; Häsler, B. Overview of evidence of antimicrobial use and antimicrobial resistance in the food chain. Antibiotics 2020, 9, 49.

9. Fisher, T. Management of Slow Growing Broilers for Profit. Available in: http://midwestpoultry. com/wp- 
content/uploads/Fisher-Tatijana. pdf. Consulted 29th January 2019.

10. Pandey, A.K.; Kumar, P.; Saxena, M.J. Feed Additives in Animal Health. In Nutraceuticals in Veterinary Medicine; Springer, 2019; pp. 345-362.

11. Singh, J.; Gaikwad, D.S. Phytogenic Feed Additives in Animal Nutrition. In Natural Bioactive Products in Sustainable Agriculture; Springer, 2020; pp. 273-289.

12. Oladeji, I.S.; Adegbenro, M.; Osho, I.B.; Olarotimi, O.J. The Efficacy of Phytogenic Feed Additives in Poultry Production: A Review. Turkish Journal of Agriculture-Food Science and Technology 2019, 7, 20382041.

13. Pirgozliev, V.; Mansbridge, S.C.; Rose, S.P.; Lillehoj, H.S.; Bravo, D. Immune modulation, growth performance, and nutrient retention in broiler chickens fed a blend of phytogenic feed additives. Poultry science 2019, 98, 3443-3449.

14. Windisch, W.; Schedle, K.; Plitzner, C.; Kroismayr, A. Use of phytogenic products as feed additives for swine and poultry. Journal of animal science 2008, 86, E140--E148.

15. Yimer, E.M.; Tuem, K.B.; Karim, A.; Ur-Rehman, N.; Anwar, F. Nigella sativa L.(black cumin): a promising natural remedy for wide range of illnesses. Evidence-Based Complementary and Alternative Medicine 2019, 2019.

16. Koç, A.; Güven, N.; Öztürk, S.B.; Dedeo\uglu, B.D.; Feyza, H.; Büyükhelvacigil, R.B.; Koparal, B. Therapeutic Trials of Nigella sativa. Journal of Pharmacy and Pharmacology 2019, 7, 564-577.

17. Ghaly, M.H.; Elghoneimy, A.A.; Mohamed, H.K.; Ali, M.F. Biochemical and histopathological effects of dietary supplementation of Nigella sativa and Mentha piperita oils to broilers. Journal of Advanced Veterinary Research 2017, 7, 7-15.

18. Saleh, A.A.; Ebeid, T.A.; Abudabos, A.M. Effect of dietary phytogenics (herbal mixture) supplementation on growth performance, nutrient utilization, antioxidative properties, and immune response in broilers. Environmental Science and Pollution Research 2018, 25, 14606-14613.

19. Akbar, S. Nigella sativa L.(Ranunculaceae). In Handbook of 200 Medicinal Plants; Springer, 2020; pp. 12871312.

20. Arif, S. Biological Evaluation and Comparison of Nigella sativa (Kalonji) and Trachyspermum ammi (Ajwain), CAPITAL UNIVERSITY, 2019.

21. Srinivasan, K. Cumin (Cuminum cyminum) and black cumin (Nigella sativa) seeds: traditional uses, chemical constituents, and nutraceutical effects. Food quality and safety 2018, 2, 1-16.

22. Hussain, D.A.; Hussain, M.M. Nigella sativa (black seed) is an effective herbal remedy for every disease except death-a Prophetic statement which modern scientists confirm unanimously: a review. Adv Med Plant Res 2016, 4, 27-57. 
23. Abdallah, E.M. Black Seed (Nigella sativa) as antimicrobial drug: a mini-review. Novel Approches in Drug Designing and Develop 2017, 3, 1-5.

24. Majdalawieh, A.F.; Fayyad, M.W.; Nasrallah, G.K. Anti-cancer properties and mechanisms of action of thymoquinone, the major active ingredient of Nigella sativa. Critical reviews in food science and nutrition 2017, 57, 3911-3928.

25. Majdalawieh, A.F.; Fayyad, M.W. Recent advances on the anti-cancer properties of Nigella sativa, a widely used food additive. Journal of Ayurveda and integrative medicine 2016, 7, 173-180.

26. Ahmed, A.F.; He, N.; Xia, Z.; Kang, W.-Y. TOTAL PHENOLIC AND FLAVONIOD CONTENT AND ANTIOXIDANT PROPERTIES OF NIGELLA SATIVA L. SEEDS. Current topics in nutraceutical research 2018, 16 .

27. Ikhsan, M.; Hiedayati, N.; Maeyama, K.; Nurwidya, F. Nigella sativa as an anti-inflammatory agent in asthma. BMC Research Notes 2018, 11, 1-5.

28. Georgescu, M.; T\uap \ualoag \ua, P.R.; T\uap \ualoag \ua, D.; Furnaris, F.; Ginghin \ua, O.; Negrei, C.; Giuglea, C.; B \ual \ual \uau, C.; Ștef $\backslash$ uanescu, E.; Popescu, I.A.; et al. Evaluation of antimicrobial potential of Nigella sativa oil in a model food matrix. Farmacia 2018, 66, 1028-1036.

29. Bekta \cs, Z.H.; Sava \cser, S.; Akçimen, U.; Ceylan, M.; Yener, O.; Bulut, C. Using of black cumin seed powder (Nigella sativa) as immunostimulant and growth promoter in rainbow trout, oncorhynchus mykiss (Walbaum). Turkish Journal of Fisheries and Aquatic Sciences 2019, 19, 987-999.

30. Selvaraju, A.; Dhanraj, S. Phytochemical analysis and anthelmintic potential of Nigella sativa against the trematode, Cotylophoron cotylophorum. Journal of Pharmacognosy and Phytochemistry 2019, 8, 3161-3166.

31. Kumar, P.; Patra, A.K. Beneficial uses of black cumin (Nigella sativa L.) seeds as a feed additive in poultry nutrition. World's Poultry Science Journal 2017, 73, 872-885.

32. Seidavi, A.R.; Laudadio, V.; Khazaei, R.; Puvača, N.; Selvaggi, M.; Tufarelli, V. Feeding of black cumin (Nigella sativa L.) and its effects on poultry production and health. World's Poultry Science Journal 2020, $1-12$.

33. Kumar, P.; Patra, A.K.; Mandal, G.P.; Debnath, B.C. Carcass characteristics, chemical and fatty acid composition and oxidative stability of meat from broiler chickens fed black cumin (Nigella sativa) seeds. Journal of animal physiology and animal nutrition 2018, 102, 769-779.

34. Abou-Elkhair, R.; Selim, S.; Hussein, E. Effect of supplementing layer hen diet with phytogenic feed additives on laying performance, egg quality, egg lipid peroxidation and blood biochemical constituents. Animal nutrition 2018, 4, 394-400.

35. Tavakkoli, A.; Ahmadi, A.; Razavi, B.M.; Hosseinzadeh, H. Black seed (Nigella sativa) and its constituent thymoquinone as an antidote or a protective agent against natural or chemical toxicities. Iranian journal of pharmaceutical research: IJPR 2017, 16, 2. 
36. Dajani, E.Z.; Shahwan, T.G.; Dajani, N.E. Overview of the preclinical pharmacological properties of Nigella sativa (black seeds): a complementary drug with historical and clinical significance. J. Physiol. Pharmacol 2016, 67, 801-817.

37. Soleimani, V.; Sahebkar, A.; Hosseinzadeh, H. Turmeric (Curcuma longa) and its major constituent (curcumin) as nontoxic and safe substances. Phytotherapy Research 2018, 32, 985-995.

38. Omosa, L.K.; Midiwo, J.O.; Kuete, V. Curcuma longa. In Medicinal Spices and Vegetables from Africa; Elsevier, 2017; pp. 425-435.

39. Nelson, K.M.; Dahlin, J.L.; Bisson, J.; Graham, J.; Pauli, G.F.; Walters, M.A. The essential medicinal chemistry of curcumin: miniperspective. Journal of medicinal chemistry 2017, 60, 1620-1637.

40. Rathore, S.; Mukim, M.; Sharma, P.; Devi, S.; Nagar, J.C.; Khalid, M. Curcumin: A Review for Health Benefits. International Journal of Research and Review 2020, 7, 273-290.

41. Ahmed, M.; Srivastava, U.; Gupta, C. Turmeric: Biological Operations and Medicinal Applications. In Ethnopharmacological Investigation of Indian Spices; IGI Global, 2020; pp. 163-172.

42. Ibrahim, J.; Kabiru, A.Y.; Abdulrasheed-Adeleke, T.; Lawal, B.; Adewuyi, A.H. Antioxidant and hepatoprotective potentials of curcuminoid isolates from turmeric (Curcuma longa) rhizome on CCl4induced hepatic damage in Wistar rats. Journal of Taibah University for Science 2020, 14, 908-915.

43. Sadashiva, C.T.; Hussain, H.M.F.; Nanjundaiah, S. Evaluation of hepatoprotective, antioxidant and cytotoxic properties of aqueous extract of turmeric rhizome (Turmesac). Journal of Medicinal Plants Research 2019, 13, 423-430.

44. Tejada, S.; Manayi, A.; Daglia, M.; F Nabavi, S.; Sureda, A.; Hajheydari, Z.; Gortzi, O.; Pazoki-Toroudi, H.; M Nabavi, S. Wound healing effects of curcumin: A short review. Current pharmaceutical biotechnology 2016, 17, 1002-1007.

45. Xiang, H.; Zhang, L.; Yang, Z.; Chen, F.; Zheng, X.; Liu, X. Chemical compositions, antioxidative, antimicrobial, anti-inflammatory and antitumor activities of Curcuma aromatica Salisb. essential oils. Industrial Crops and Products 2017, 108, 6-16.

46. Ilangovan, M.; Guna, V.; Hu, C.; Nagananda, G.S.; Reddy, N. Curcuma longa L. plant residue as a source for natural cellulose fibers with antimicrobial activity. Industrial crops and products 2018, 112, 556-560.

47. Singh, N.; Gupta, S.; Rathore, V. Comparative antimicrobial study of ethanolic extract of leaf and rhizome of curcuma longa linn. Pharmacognosy Journal 2017, 9.

48. Alsamydai, A.; Jaber, N. Pharmacological aspects of curcumin. Int J Pharm 2018, 5, 313-326.

49. Hu, Y.; Zhang, J.; Kong, W.; Zhao, G.; Yang, M. Mechanisms of antifungal and anti-aflatoxigenic properties of essential oil derived from turmeric (Curcuma longa L.) on Aspergillus flavus. Food chemistry 2017, 220, 1-8. 
50. Shakeri, A.; Ward, N.; Panahi, Y.; Sahebkar, A. Anti-angiogenic activity of curcumin in cancer therapy: a narrative review. Current vascular pharmacology 2019, 17, 262-269.

51. Sani, I.; Argungu, A.U.; Jiga, S.A.; Bello, F.; Abdulhamid, A.; Sulaiman, A.; Aminu, H.; Mungadi, S.I. Phyto-Peptides as Anti-Snake Venom Agents. 2019.

52. Mehala, C.; Moorthy, M. Effect of Aloe vera and Curcuma longa (Turmeric) on carcass characteristics and biochemical parameters of broilers. Int. J. Poult. Sci 2008, 7, 857-861.

53. Ahlawat, P.K. Effect of Supplementation of Turmeric Powder (Curcuma longa) on Growth Performance, Gut Morphology and Meat Quality of Broilers, UNIVERSITY OF VETERINARY AND ANIMAL SCIENCES, 2017.

54. Zhang, Y.; Wulumuhan, N.; Gong, F.; Entomack, B.; others Construction and characterization of an acapsular mutant of Pasteurella multocida strain P-1059 (A: 3). Journal of Vaccines and Vaccination 2013, 4.

55. Marcu, A.; Vacaru-Opri \cs, I.; Dumitrescu, G.; Ciochina, L.P.; Marcu, A.; Nicula, M.; Pe \ct, I.; Dronca, D.; Kelciov, B. The influence of the genotype on economic efficiency of broiler chickens growth. Scientific Papers Animal Science and Biotechnologies 2013, 46, 339-346.

56. Abdallah, A.A.M.; Nasr El-Deen, N.A.M.; Abd El-Aziz, H.I.; Neamat-Allah, A.N.F. Effect of the aqueous root extract of Curcuma longa L.(turmeric) against thermally oxidized oil-induced hematological, biochemical and histopathological alterations. Comparative Clinical Pathology 2020, 1-9.

57. Awad, W.A.; Ghareeb, K.; Abdel-Raheem, S.; Böhm, J. Effects of dietary inclusion of probiotic and synbiotic on growth performance, organ weights, and intestinal histomorphology of broiler chickens. Poultry science 2009, 88, 49-56.

58. Kokate, L.S.; Kumar, S.; Rahim, A.; Das, A.K. Estimating serological immune response against Newcastle disease vaccine in Aseel, Kadaknath and White Leghorn chicken using haemagglutination inhibition test. Ind J Anim Sci 2017, 87, 136-138.

59. Wambura, P.N.; Mzula, A. A novel rapid direct haemagglutination-inhibition assay for measurements of humoral immune response against non-haemagglutinating Fowlpox virus strains in vaccinated chickens. Heliyon 2017, 3, e00428.

60. Hermes, I.H.; Attia, F.M.; Ibrahim, K.A.; El-Nesr, S.S. Physiological responses of broiler chickens to dietary different forms and levels of nigella sativa 1., during egyptian summer season. J. Agri. and Vet. Sci 2011, 4, 17-33.

61. GHALY, S.; AWADIN, W.; ELSAWAK, A. Pathological and Immunohistochemical Study of P. Multocida Capsular Type a in Tissues of Chickens and Ducks Infected with Fowl Cholera. Assiut Veterinary Medical Journal 2017, 63, 1-18.

62. Tang, Q.; Li, W.; Dai, N.; Gao, Y.; Han, Y.; Cheng, G.; Gu, C. The Role of Necroptosis, Apoptosis, and Inflammation in Fowl Cholera--Associated Liver Injury in a Chicken Model. Avian diseases 2017, 61, 491- 
502.

63. Arslan, M.; Haq, A.; Ashraf, M.; Iqbal, J.; Mund, M.D. Effect of turmeric (Curcuma longa) supplementation on growth performance, immune response, carcass characteristics and cholesterol profile in broilers. Veterinaria $\mathbf{2 0 1 7}, 66, \mathbf{1 6}-19$.

64. Shamim Molla, M.; Azad, A.K.; Al Hasib, M.A.A.; Hossain, M.M.; Ahammed, M.S.; Rana, S.; Islam, M.T. A REVIEW ON ANTIVIRAL EFFECTS OF NIGELLA SATIVA L. 2019.

65. Al-Mufarrej, S.I. Immune-responsiveness and performance of broiler chickens fed black cumin (Nigella sativa L.) powder. Journal of the Saudi Society of Agricultural Sciences 2014, 13, 75-80.

66. Fallah, R.; Mirzaei, E.; others Effect of dietary inclusion of turmeric and thyme powders on performance, blood parameters and immune system of broiler chickens. Livest. Sci 2016, 7, 180-186.

67. Dair, H.F.; Ali, A.M.M. Immunomodulatory effects of levamisole hydrochloride and Nigella sativa against infectious bursal disease (IBD) in chicks. Microbiology Research International 2016, 4, 17-27.

68. Choudhury, D.; Mahanta, J.; Sapcota, D.; Saikia, B.; Islam, R. Effect of dietary supplementation of turmeric (Curcuma longa) powder on the performance of commercial broiler chicken. International Journal of Livestock Research 2017, 7, 1964-2277.

69. Ürü \csan, H.; Bölükba \cs \i, \cS Canan Effects of dietary supplementation levels of turmeric powder (Curcuma longa) on performance, carcass characteristics and gut microflora in broiler chickens. J. Anim. Plant Sci 2017, 27, 732-736.

70. Tehseen, M.; Tahir, M.; Khan, R.U.; Jabbar, A.; Ahmad, B.; Ahsan, T.; Khan, M.S.; Khan, S.; Abudabos, A.M. Additive effect of Nigella sativa and Zingiber officinale herbal mixture on performance and cholesterol profile in broiler. Philip Agric Sci 2016, 99, 408-413.

71. Kumar, P.; Patra, A.K.; Mandal, G.P.; Samanta, I.; Pradhan, S. Effect of black cumin seeds on growth performance, nutrient utilization, immunity, gut health and nitrogen excretion in broiler chickens. Journal of the Science of Food and Agriculture 2017, 97, 3742-3751.

72. Islam, M.T.; Khan, M.R.; Mishra, S.K. An updated literature-based review: phytochemistry, pharmacology and therapeutic promises of Nigella sativa L. Oriental Pharmacy and Experimental Medicine 2019, 1-15.

73. Dubey, P.N.; Singh, B.; Mishra, B.K.; Kant, K.; Solanki, R.K. Nigella (Nigella sativa L.): A high value seed spice with immense medicinal potential. Indian J. Agric. Sci 2016, 86, 967-979.

74. Lim, T.K. Curcuma longa. In Edible Medicinal and Non-Medicinal Plants; Springer, 2016; pp. 241-362.

75. Hosseini, S.M.; Taghiabadi, E.; Abnous, K.; Hariri, A.T.; Pourbakhsh, H.; Hosseinzadeh, H. Protective effect of thymoquinone, the active constituent of Nigella sativa fixed oil, against ethanol toxicity in rats. Iranian Journal of Basic Medical Sciences 2017, 20, 927. 
76. Vaughn, A.R.; Branum, A.; Sivamani, R.K. Effects of turmeric (Curcuma longa) on skin health: a systematic review of the clinical evidence. Phytotherapy Research 2016, 30, 1243-1264.

77. Rahmani, A.H.; Alsahli, M.A.; Aly, S.M.; Khan, M.A.; Aldebasi, Y.H. Role of curcumin in disease prevention and treatment. Advanced biomedical research 2018, 7 .

78. Abdollahi, E.; Momtazi, A.A.; Johnston, T.P.; Sahebkar, A. Therapeutic effects of curcumin in inflammatory and immune-mediated diseases: A nature-made jack-of-all-trades? Journal of cellular physiology 2018, 233, 830-848. 